\title{
Method for Determining Anaerobic Fermentation of Mannitol by Staphylococci
}

\author{
JAMES B. EVANS AND CHRIS A. PATE \\ Department of Microbiology, North Carolina State University, Raleigh, North Carolina 27650
}

\begin{abstract}
The effects of different media constituents and methods of achieving anaerobiosis were determined. Best results were obtained with a liquid medium containing a protein digest, yeast extract, and bromocresol purple and with a Vaspar seal for maintaining anaerobiosis. The major problem encountered was inhibition of mannitol fermentation in some cultures when alcoholic stock solutions of bromocresol purple were used in preparation of the media.
\end{abstract}

The ability to ferment mannitol under anaerobic conditions (2) remains one of the major taxonomic criteria for the species Staphylococcus aureus (1). However, numerous variations in basal medium and in the method of achieving anaerobiosis have been employed by different investigators. There are disagreements concerning the taxonomic validity of the test, some undoubtedly attributable to differences in methodology. The International Subcommittee on Taxonomy of Staphylococci and Micrococci (7) attempted to establish a standard method for this and other tests. Kocur and Mortensen (4) compared the proposed standard method with several other methods employed by other investigators. They found a good correlation between results obtained with the standard method and two of the other methods: the production of a final $\mathrm{pH}$ of 5.0 or below in the medium of Evans, Bradford, and Niven (3), and a strong acid production in the medium of Mossel and Martin (5). Other methods were less satisfactory. The standard method employed a semisolid agar medium that was inoculated by stabbing and covered with a layer of sterile paraffin oil. Mossel and Martin used a solid medium inoculated by stabbing, and Evans et al. used a liquid medium incubated in an anaerobic jar. The first two media used bromocresol purple (BCP) as the $\mathrm{pH}$ indicator, and Evans et al. measured $\mathrm{pH}$ with an electronic meter. All three of these methods are cumbersome and subject to variations in the degree of anaerobiosis achieved. The present study was designed to determine the effects of variations in media constituents and methods of anaerobiosis on the results of the test.

\section{MATERIALS AND METHODS}

Bacterial strains. Most experiments employed five strains of $S$. aureus: ATCC 12600 (the type strain), SUS 596 (a swine isolate), 408+ and Rd4 (bovine isolates), and 4025 (from osteoarthritis in a chicken). The first four strains were obtained from W. E. Kloos, Department of Genetics, North Carolina State Uni- versity, and the fifth strain was obtained from W. M. Colwell, Holly Farms Poultry Industries. A collection of $S$. aureus strains from poultry and stock cultures of Staphylococcus hyicus, Staphylococcus intermedius, and Staphylococcus epidermidis were included in the final evaluation of our recommended medium and method.

Media. Several commercially available media from BBL Microbiology Systems were used in this study, including purple broth base, Trypticase soy broth, and brain heart infusion broth. Other media were prepared from ingredients from BBL and Difco Laboratories. Test media were adjusted to $\mathrm{pH} 7.0$, tubed in $8-\mathrm{ml}$ volumes in 16 - by $150-\mathrm{mm}$ tubes, sterilized at $15 \mathrm{lb} / \mathrm{in}^{2}$ for $15 \mathrm{~min}$, and inoculated within a few hours after preparation.

\section{RESULTS}

Inocula. Inocula were grown for $24 \mathrm{~h}$ at $37^{\circ} \mathrm{C}$ in Trypticase soy broth, brain heart infusion broth and Trypticase soy broth plus $0.1 \%$ yeast extract. Superior growth, measured as optical density, was obtained in brain heart infusion broth and Trypticase soy broth plus $0.1 \%$ yeast extract, and the latter was selected to grow the inocula for subsequent experiments. Several experiments compared the use of a 1-drop inoculum with a loop inoculation, and no significant differences in results were noted.

Protein digest. Protein digests employed at the $1.0 \%$ level included Trypticase (BBL), Gelysate (BBL), peptone (Difco), tryptone (Difco), and proteose-peptone no. 3 (Difco). These were tested separately and with $0.1 \%$ yeast extract added. In the absence of yeast extract, none of the peptones supported good acid production by one or more of the test cultures. With the addition of $0.1 \%$ yeast extract, best results were obtained with Trypticase and tryptone.

Yeast extract. Addition of $0.1 \%$ yeast extract, as noted above, eliminated a number of negative and weak reactions obtained in protein digest media. The addition of $0.5 \%$ yeast extract provided sufficient fermentable substrate so that 
significant acid was produced by some of the cultures in the basal medium without adding mannitol.

pH indicator. BCP (Difco) was used in all media. The method of preparing and adding this indicator was found to be the major contributor to false-negative results in the various test media. In most experiments, a final concentration of $0.004 \%$ BCP was used. If this was achieved by adding $2 \mathrm{ml}$ of a $0.2 \%$ alcoholic solution of BCP per $100 \mathrm{ml}$ of medium before autoclaving, acid production by all cultures was inhibited in all media. If $0.2 \mathrm{ml}$ of a $2.0 \%$ alcoholic solution of BCP was added per $100 \mathrm{ml}$, fermentation of mannitol by all cultures was inhibited, and the rate of fermentation of glucose was decreased. The addition of $0.1 \mathrm{ml}$ of a $2.0 \%$ alcoholic solution of BCP per $100 \mathrm{ml}$ inhibited or slowed mannitol fermentation in most media, but did not affect glucose fermentation. When the BCP was dissolved in dilute alkali $(18.5 \mathrm{ml}$ of $0.01 \mathrm{M}$ $\mathrm{NaOH}$ per $100 \mathrm{mg}$ ) and added at the $0.004 \%$ level ( $2 \mathrm{ml}$ of $0.2 \%$, or $0.2 \mathrm{ml}$ of $2.0 \%$, per 100 $\mathrm{ml}$ ), there was no inhibition of mannitol fermentation by the test strains. However, when 12 strains of $S$. aureus from poultry and 5 strains from other sources were tested, some strains were slower to produce acid in media with $0.004 \%$ BCP than when $0.002 \%$ BCP was used. At the end of 7 days, some strains were positive in the latter medium and negative in the former. After 10 days of incubation, only one showed this difference

Agar. The semisolid agar standard methods medium was compared with a fluid medium of the same nutrient composition; a Vaspar seal was used to maintain anaerobiosis in both media. All of these test cultures gave positive results in both media, although the results were somewhat more rapid in the broth medium.

Anaerobiosis. Best results were obtained by covering the freshly inoculated media with approximately a $1-\mathrm{cm}$ layer of melted sterile Vaspar (a mixture of equal parts of paraffin, mp $48^{\circ} \mathrm{C}$, and white petrolatum, autoclaved in tubes for $60 \mathrm{~min}$ at $15 \mathrm{lb} / \mathrm{in}^{2}$ ). Gentle heating of the tube at the level of the seal may improve the seal. Use of liquid culture media with Vaspar seals was less cumbersome and gave sharper and more repeatable results than did stab cultures in semisolid agar with paraffin oil seals. Liquid cultures in GasPak (BBL Microbiology Systems) jars gave good results but were more cumbersome to set up.

\section{DISCUSSION}

Based on the results obtained in this study, several modifications in the standard method of determining the anaerobic fermentation of man- nitol (or other substrates) by staphylococci are recommended. It is proposed that a liquid medium (prepared by omitting the agar from the standard methods medium), a 1-drop inoculum, and a petrolatum-paraffin (Vaspar) seal to maintain anaerobiosis be used. Particular care should be exercised with the BCP: an aqueous stock solution, rather than an alcoholic stock solution such as was recommended in the Manual of Microbiological Methods (6), should be used. A final concentration of $0.002 \% \mathrm{BCP}$ will give slightly better results with some strains, particularly those from poultry. Incubation for 10 days at $37^{\circ} \mathrm{C}$ will permit full acid production by most, if not all, of the slow fermenters. When the same basal medium and methods were used with glucose as the substrate, positive results usually were shown within 1 day.

Modifications in inoculum size, tube size, and volume of medium per tube should not bring about significant changes in results. Laboratories with equipment for routine culturing under anaerobic conditions should also be able to substitute their method for the Vaspar seal, particularly when the test is being conducted for diagnostic purposes rather than for basic taxonomic studies.

\section{ACKNOWLEDGMENTS}

We thank W. E. Kloos and W. M. Colwell for supplying the cultures used in this study. This research was supported by the North Carolina Agricultural Research Service and is paper no. 6273 of their Journal Series.

\section{REPRINT REQUESTS}

Address reprint request to: Dr. J. B. Evans, Department of Microbiology, North Carolina State University, Raleigh, NC 27650.

\section{LITERATURE CITED}

1. Baird-Parker, A. C. 1974. Genus II. Staphylococcus Rosenbach 1884, 18 nom. cons. Opin. 17 Jud. Comm. 1958, 153, p. 483-489. In R. E. Buchanan and N. E. Gibbons (ed.), Bergey's manual of Determinative Bacteriology, 8th ed., The Williams \& Wilkins Co., Baltimore.

2. Evans, J. B. 1947. Anaerobic fermentation of mannitol by staphylococci. J. Bacteriol. 54:266.

3. Evans, J. B., W. L. Bradford, Jr., and C. F. Niven, Jr. 1955. Comments concerning the taxonomy of the genera Micrococcus and Staphylococcus. Int. Bull. Bacteriol. Nom. Taxon. 5:61-66.

4. Kocur, M., and N. Mortensen. 1967. Comparison of methods for estimation of anaerobic production of acid from glucose and mannitol in staphylococci and micrococci. Acta Path. Microbiol. Scandinav. 71:141-146.

5. Moseel, D. A. A., and G. Martin. 1961. Milieu simplifie permettant l'etude des divers modes d'action des bacteries sur les hydrates de carbone. Ann. Inst. Pasteur Lille. 12:225-226.

6. Society of American Bacteriologists. 1957. Manual of microbiological methods. McGraw-Hill Book Co., Inc., New York.

7. Subcommittee on Taxonomy of Staphylococci and Micrococci. 1965. Recommendations. Int. Bull. Bacteriol. Nom. Taxon. 15:109-110. 